\title{
OPTIMIZING Cu REMOVAL/RECOVERY IN A BIOSORPTION COLUMN
}

\author{
DAVID KRATOCHVIL', BOHUMIL VOLESKY ${ }^{\prime *}$ and GEORGE DEMOPOULOS
}

'Department of Chemical Engineering, 'Department of Mining and Metallurgical Engineering, McGill

University, 3480 University Street, Montreal, Québec, Canada H3A 2A7

(First received June 1996; accepted in revised form February 1997)

\begin{abstract}
Biosorption of $\mathrm{Cu}^{2+}$ by Sargassum fluitans seaweed biomass protonated by an acidic wash or loaded with $\mathrm{Ca}^{2+}$ is based on ion exchange. The uptake of $\mathrm{Cu}^{2+}$ is respectively accompanied by a release of either $\mathrm{H}^{+}$or $\mathrm{Ca}^{2+}$ into the solution phase. The effects of $\mathrm{Ca}-\mathrm{H}$ - and $\mathrm{H} / \mathrm{Ca}$-cycles on the performance of a continuous-flow biosorption fixed-bed were established. The Ca-cycle applied to Sargassum biomass in a packed bed led to a high degree of a column utilization but did not allow an effective Cu recovery. The $\mathrm{H}$-cycle permitted $100 \% \mathrm{Cu}$ recovery but also shortened the sorption column service time. The combined $\mathrm{Ca} / \mathrm{H}$-cycle was shown to be inefficient due to the time consuming regeneration of biomass from the $\mathrm{H}$-form to the Ca-form. Biomass pretreatment with $1 \%(w)$ solution of $\mathrm{CaCl}_{2}$ and with $0.1 \mathrm{M} \mathrm{HCl}$ resulted in the same $\mathrm{Cu}$ uptake of $75 \mathrm{mg} / \mathrm{g}$. The Ca-pretreated biomass lost approximately $30 \%$ of its $\mathrm{Cu}$ capacity with subsequent acidic wash. The equilibrium aspects of $\mathrm{Cu}$ removal and recovery in a biosorption column were analyzed through the concept of ion-exchange isotherms. The dynamics of $\mathrm{Cu}$ sorption and of biomass regeneration in a fixed-bed column was predicted by numerically solving the equations of a proposed ion-exchange model. (C) 1997 Elsevier Science Ltd
\end{abstract}

Key words-biosorption, ion-exchange, $\mathrm{Cu}$ removal. $\mathrm{Cu}$ recovery, fixed-bed column, regeneration

\section{NOMENCLATURE}

$a, b=$ stoichiometric coefficients in the ionexchange reaction equation (5)

$A, B=$ species in the resin phase

$\mathrm{A}, \mathrm{B}=$ species in the liquid

$C_{0}=$ normality of the solution (meq/liter)

$C_{C N T}=$ equivalent fraction of counterion in liquid phase

$C_{\text {CNTO }}=$ equivalent fraction of counterion in the feed to a column

$C_{\mathrm{PM}}=$ equilibrium final concentration of species $M$ in liquid phase (meq/liter)

$C_{\mathrm{M}}=\mathrm{x}_{\mathrm{M}}=$ equivalent fraction of species $\mathrm{M}$ in liquid phase

$C_{\mathrm{M} 1}=$ equivalent fraction of species $M$ in the feed to a column

$C_{\mathrm{ML}}=$ concentration of species $\mathbf{M}$ in liquid phase (meq/liter)

$C_{t}=$ concentration of binding sites in biomass (meq/g)

$D_{Z}=$ axial dispersion coefficient $\left(\mathrm{cm}^{2} / \mathrm{s}\right)$

$K_{\mathrm{AB}}=$ ion-exchange equilibrium constant

$K_{\mathrm{fM}}=$ overall mass transfer coefficient of species $\mathrm{M}\left(\mathrm{min}^{-1}\right)$

$K_{\mathrm{H}}, K_{\mathrm{M} 1}, K_{\mathrm{M} 2}=$ equilibrium constants of biosorption equilibrium model

$l=$ vertical distance from the top of a column

$L_{0}=$ length of the column $(\mathrm{cm})$

$M_{\text {wCNT }}=$ molecular weight of the counterion

$M_{\mathrm{wM}}=$ molecular weight of the sorbing metal

*Author to whom all correspondence should be addressed [E-mail: boya (a chemeng.lan.mcgill.ca].

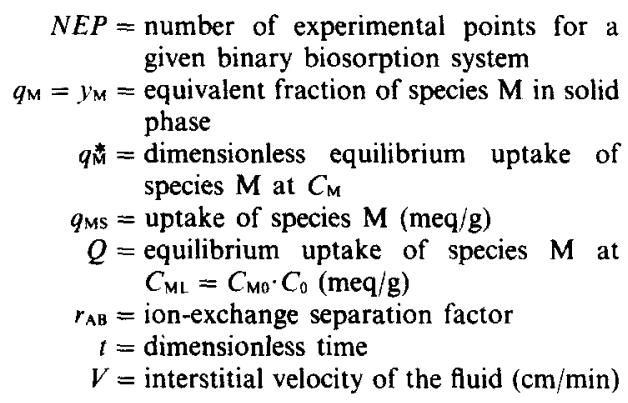

Greek symbols

$\epsilon=$ column void fraction

$v=$ stoichiometric coefficient of the exchange reaction

$\rho_{\mathrm{b}}=$ packing density $(\mathrm{g} /$ liter $)$

$\tau=$ time (min)

Dimensionless groups

$D_{\mathrm{BM}}=\rho_{\mathrm{b}} Q / C_{0} \epsilon=$ solute distribution parameter

$P e_{\mathrm{c}}=L_{0} v / D_{\mathrm{z}}=$ column Peclet number

$S h_{\mathrm{M}}=K_{\mathrm{Im}} L_{0} / v=$ modified Sherwood number

\section{INTRODUCTION}

Aqueous heavy-metal pollution represents an important environmental issue. Although the removal of toxic heavy metals from industrial waste-waters has been addressed for many years, the effectiveness of the commonly employed treatment of metal-bearing effluents remains limited. Chemical precipitation leads to the production of toxic sludges. Due to the 
economics of dealing with large volumes of liquids and of solvent losses, solvent extraction is limited to streams containing more than $1 \mathrm{~g} / \mathrm{l}$ of the targeted heavy metal. Application of the ion-exchange process is rather expensive due to the cost of synthetic ion-exchange resins. Furthermore, the ion-exchange resins are not always selective enough to allow an effective recovery of heavy metals present in the waste.

Biosorption is known as a water purification process whereby toxic heavy metals are sequestered from diluted aqueous solutions, by sorption onto inexpensive biological materials such as non-living freshwater and marine algae, yeast, fungi and bacteria. Recent studies revealed that uptakes of divalent metals including $\mathrm{Cu}, \mathrm{Zn}$ and $\mathrm{Cd}$ by algal biomass (Crist et al., 1994; Schiewer and Volesky, 1995b) and by various species of filamentous fungi (Fourest and Roux, 1994) are accompanied by a release of ionic species from the biosorbents. On-going research into the metal binding by brown algae identified carboxyl groups of alginate and sulfonate groups of sulfated polysaccharides as the two key types of binding sites readily participating in ion-exchange reactions (Fourest and Volesky, 1996). The similarity between biosorption and ion exchange indicates that biomass can exist in different ionic forms and that, consequently, algal biosorbents involved in a continuous metal removal and recovery can operate on different ionic cycles, such as the $\mathrm{H}$-, $\mathrm{Ca}-\mathrm{H} / \mathrm{Ca}-\mathrm{Na}-\mathrm{cycle}$, etc. In process applications, the most effective apparatus for cyclic sorption/desorption is a fixed-bed column, as the fixed bed makes the best use of the concentration difference known to be a driving force for heavy-metal uptake. An ionic form of biomass can affect the sorption capacity, the selectivity, the chemical stability and the physical properties of the biosorbent. Furthermore, an ionic cycle influences the degree of a sorption column utilization and the efficiency with which a given heavy metal can be recovered (Helfferich, 1962). While the metal sorption capacity of some types of fungal biomass including Rhizopus arrhizus and Penicillium chrysogenum was demonstrated to possess a strong dependence on the ionic form of the biomass (Fourest and Roux, 1994), the biosorbent capacity of the marine alga Sargassum fluitans was almost unaffected by the presence of different light metals such as $\mathrm{Ca}$, $\mathrm{Mg}, \mathrm{Na}$ and $\mathrm{K}$ at relatively low concentrations of the heavy metal in water (Kratochvil et al., 1995). However, the effect of the biomass ionic form on the metal sorption capacity of $S$. fluitans has not been studied systematically, i.e. taking into account not only the values of metal-ion uptakes but also the weight losses caused by different pretreatments used to convert the raw biomass into biosorbent material of a desired ionic form. Moreover, due to a relatively high content of alginate in brown seaweed (Chapman, 1980), the ionic form plays a crucial role in the stabilization of $S$. fluitans, in that
$\mathrm{Na}^{+}$and $\mathrm{K}^{+}$solubilize its constituent alginate whereas $\mathrm{H}^{+}$and $\mathrm{Ca}^{2+}$ keep the alginate inside the biomass in the form of insoluble alginic acid and crosslinked Ca-alginate, respectively (Thom et al., 1982).

The objective of the present work was to optimize the biosorption of $\mathrm{Cu}$ by $S$. fluitans in a fixed-bed column. The optimization was mainly concerned with the selection of an ionic cycle for the biomass packed in the column while taking into account the effects of biosorbent pretreatment. Although the process of $\mathrm{Cu}$ biosorption in a fixed-bed column is influence by both the sorption equilibrium and the mass transfer, the present column experimental data were interpreted mainly through the concept of ion-exchange equilibrium isotherms calculated from a model originally developed for biosorption by algal biomass (Schiewer and Volesky, 1995b). The effect of mass transfer was not studied; however, some of the column data were used for fitting a fixed-bed ion-exchange model recently used by Tan and Spinner (Tan and Spinner, 1994). The literature on modeling of biosorption in a fixed bed is rather scarce, and the few models that were applied (Trujillo et al., 1991; Volesky and Prasetyo, 1994) approached the biosorption process as the adsorption on activated carbon.

The lack of information on biosorption in columns is partly due to the fact that the metal uptake by different biomaterials is still not fully understood and partly because most of the biomasses have to be immobilized, granulated or otherwise processed before their use in a column. The fairly rigid body of the Sargassum seaweed, however, allows the use of the whole algal biomass after only a simple pretreatment consisting of soaking of the biomass in aqueous solutions followed by a wash with water. The purpose of the pretreatment of the raw $S$. fluitans is to flush out the impurities while converting the algal biomass into the desired ionic form.

\section{MATERIALS AND METHODS}

Raw biomass

Biomass of the brown marine alga $S$. fluitans was collected beach-dried on the Gulf Coast of Florida (USA) in August.

\section{Pretreatment}

The following aqueous solutions were selected for the pretreatment of the biomass: $1 \%(w) \mathrm{CaCl}_{2}, 0.1 \mathrm{M} \mathrm{HCl}, 1 \mathrm{M}$ $\mathrm{HCl}, 0.05 \mathrm{M} \mathrm{H}_{2} \mathrm{SO}_{4}$ and $1 \mathrm{M} \mathrm{H}_{2} \mathrm{SO}_{4}$. The biomass was pretreated in a batch for $3 \mathrm{~h}$ at a biomass concentration of $10 \mathrm{~g} /$ liter, then washed with approximately 1 liter $/ \mathrm{g}$ of distilled water and finally dried in the oven overnight at $60^{\circ} \mathrm{C}$. The dried biomass was weighed the next day and the weight loss was determined. $\mathrm{Cu}$ uptake experiments were carried out under controlled $\mathrm{pH}$ with biomass samples from each of the pretreatment batches. For the metal uptake experiment, the $\mathrm{CaCl}_{2}$ pretreated biomass was protonated in a solution of $0.1 \mathrm{M} \mathrm{HCl}$ for $3 \mathrm{~h}$ before being contacted with the $\mathrm{Cu}$ solution. Binary biosorption systems $(\mathrm{Cu} / \mathrm{H}, \mathrm{Cu} / \mathrm{Ca} /, \mathrm{Ca} / \mathrm{H})$ were also studied with pretreated biomass. 
Measurement of equilibrium uptakes

Approximately $0.2 \mathrm{~g}$ of biomass was contacted with $50 \mathrm{ml}$ of a metal solution in a $125-\mathrm{ml}$ Erlenmeyer flask as left in a shaker at $125 \mathrm{rpm}$ for $4 \mathrm{~h}$. Samples were taken of the initial metal solution and of the supernatant solution after the equilibration. These samples were analyzed for metal content using atomic absorption spectronomy (AAS, Perkin-Elmer 3100). The metal uptake was determined from the difference of metal concentrations in the initial and final solutions. Equilibration and $\mathrm{pH}$ control, mentioned throughout this text, mean that the biomass was kept in contact with a given solution for $4 \mathrm{~h}$ and that $\mathrm{pH} 4.5$ was being maintained by additions of $0.1 \mathrm{M} \mathrm{NaOH}$ as required.

\section{Preparation and operation of biosorption column}

A chromatography column of $2.5 \mathrm{~cm}$ internal diameter and $50 \mathrm{~cm}$ length (Canlab) was used with an adjustable plunger and two respective heights of the packing equal to 20 and $40 \mathrm{~cm}$. Dry pretreated biomass was packed into the column gradually by $5-\mathrm{cm}$ segments using a plastic piston. The resulting packing density averaged over the segments was $190 \mathrm{~g} /$ liter. The dry-packed column was slowly flooded with distilled water.

Solutions of $\mathrm{Cu}\left(\mathrm{NO}_{3}\right)_{2}$ in distilled water containing 2-3 $\mathrm{mM} \mathrm{Cu}^{2+}$ were fed to the column from the top and pumped through the fixed bed at a constant superficial velocity of $1.5 \mathrm{~cm} / \mathrm{min}$ using a peristaltic pump (Cole-Parmer). The flowrate of $7.5 \mathrm{ml} / \mathrm{min}$ through the system was indicated by a flowmeter (Dwyers) and adjusted manually by setting the speed of the pump. Samples of the column effluent were collected by a fraction collector (Gilson FC205), and the concentrations of $\mathrm{Ca}^{2+}$ and $\mathrm{Cu}^{2+}$ in the samples were determined by AAS (Perkin-Elmer 3100). The $\mathrm{pH}$ of the column influent and effluent was continuously recorded.

Desorption of $\mathrm{Cu}$ from the biomass in the column was carried out by feeding either $0.1 \mathrm{M} \mathrm{HCl}$ or $1 \%(w)$ aqueous solution of $\mathrm{CaCl}_{2}$ into the column at the flowrate of $10 \mathrm{ml} / \mathrm{min}$.

To convert the biomass from the $\mathrm{H}$-form to the $\mathrm{Ca}$-form, $1 \%$ aqueous solution of $\mathrm{CaCl}_{2}$ was recycled through the column at $7.5 \mathrm{ml} / \mathrm{min}$. A 1.5 -liter recycle solution reservoir was stirred and the $\mathrm{pH}$ of the content was controlled by additions of $\mathrm{NaOH}$.

\section{THEORETICAL APPROACH}

\section{Equilibrium model}

Biosorption. Several equilibrium models have been developed recently and applied to the biosorption of $\mathrm{Cu}$ by marine algal biomass (Chong and Volesky, 1995; Schiewer and Volesky, 1995b) and to the sorption of $\mathrm{Cu}$ onto Na-alginate (Jang et al., 1995a). The model developed by Schiewer (Schiewer and Volesky, 1995b) assumes the existence of only one type of a binding site in the biomass reacting with ions from the solution in the following manner:

$$
\mathrm{M}^{2+}+2 \mathrm{~B}=2 \mathrm{BM}_{0.5} \quad \mathrm{H}^{+}+\mathrm{B}=\mathrm{BH}
$$

It was selected for the present work for the following reasons: (1) the biosorption of $\mathrm{Cu}$ and $\mathrm{Ca}$ by $\mathrm{H}$-biomass involves an exchange of ions of unequal valence, unlike the cases treated by Chong and Volesky (1995); (2) Jang et al. (1995a, b) had to use different models for modeling systems with and without protons, whereas Schiewer's model was shown to apply equally well to both metal-metal and proton-metal binary systems (Schiewer and Volesky, 1995b, 1996); (3) the model provides explicit formulas for metal uptakes as functions of final concentrations of the species present in the system, even for the case of heterovalent exchange, which makes it especially suitable for use in numerical simulations of dynamic sorption systems; and (4) the contribution of the biomass sulfonate groups to the total binding capacity of the biomass can be considered negligible as compared to the contribution of the carboxyl groups, hence allowing the use of a model which assumes only one type of binding site. The assumption concerning the negligible contribution of the sulfonate groups is based on the fact that sulfated polysaccharides are normally extracted from seaweed under acidic conditions (Percival and McDowell. 1967) which are used during pretreatment and repetitive desorption of metals from metal-laden biomass using $\mathrm{HCl}$. The model equation for the equilibrium uptake of a bivalent metal ion Ml present in a binary system with hydrogen protons can be written as follows:

$$
q_{\mathrm{M} 1}^{*}=\frac{0.5 M_{\mathrm{WM} 1} C_{1}\left(K_{\mathrm{M} 1} C_{\mathrm{IM} 1}\right)^{1.2}}{1+K_{\mathrm{H}} C_{\mathrm{H}}+\left(K_{\mathrm{M} 1} C_{\mathrm{MM}}\right)^{1.2}}
$$

Similarly, for a binary system containing bivalent species $\mathrm{M} 1$ and $\mathrm{M} 2$, the expressions for uptakes of each of the species can be written as follows:

$$
\begin{aligned}
& q_{\mathrm{M} 1}^{*}=\frac{0.5 M_{\mathrm{WM} 1} C_{1}\left(K_{\mathrm{M} 1} C_{\mathrm{rM1}}\right)^{12}}{1+\left(K_{\mathrm{M} 1} C_{\mathrm{IM} 1}\right)^{1.2}+\left(K_{\mathrm{M} 2} C_{\mathrm{IM} 2}\right)^{1.2}} \\
& q_{\mathrm{M} 2}^{*}=\frac{0.5 M_{\mathrm{WM} 2} C_{1}\left(K_{\mathrm{M} 2} C_{\mathrm{M} 2}\right)^{12}}{1+\left(K_{\mathrm{M} 1} C_{\mathrm{M} 1}\right)^{1.2}+\left(K_{\mathrm{M} 2} C_{\mathrm{M} 2}\right)^{12}}
\end{aligned}
$$

The constants $K_{H}, K_{M}$ and $K_{\mathrm{M} 2}$ in equations (2) and (3) are equilibrium binding constants of protons and metals (Schiewer and Volesky, 1995b). The constant $C_{t}$ in equations (2) and (3) represents the density of binding sites $\mathrm{B}$ in the biomass which interact with metals $\mathbf{M}$ and protons $\mathrm{H}$ according to equation (1). The values of the parameters $C_{\mathrm{t}}, K_{\mathrm{H}}, K_{\mathrm{M} 1}$ and $K_{\mathrm{M} 2}$ can be determined by fitting the model to the experimental data using linearized forms of equations (2) and (3) and a linear regression (Jang et al., 1995b). Alternatively, non-linear programming methods applied to minimizing an objective function which expresses the deviations of the model from the later. The MWLS method introduces weights which usually reflect the reliability of the given experimental data. The weights $\left(q_{i}^{\text {exp }}\right)^{-2}$ in equation (4) were chosen so that the objective function $F_{\mathrm{M}}$ represented the sum of the squares of the relative deviations between the model and the experimental data:

$$
\text { minimize } \quad F_{\mathrm{M}}=\sum_{i=1}^{N E P}\left(\frac{q_{i}^{\mathrm{exp}}-q_{i}^{\mathrm{theor}}}{q_{i}^{\mathrm{exp}}}\right)^{2}
$$

In binary systems, the minimization is performed with respect to the uptakes of the sorbing species. The value of $C_{1}$ was determined for $S$. fluitans independently by Fourest and Volesky (1996) and Schiewer and Volesky (1995b) from $\mathrm{pH}$ and conductometric titrations of protonated biomass with 
$\mathrm{NaOH}$. In the present work, the $C_{\mathrm{t}}$ value obtained by Fourest and by Schiewer was verified by performing metal-uptake experiments at a controlled $\mathrm{pH}$.

Ion exchange. As is shown later, biosorption of $\mathrm{Cu}$ by $\mathrm{Ca}$-biomass and $\mathrm{H}$-biomass can be viewed as a simple ion exchange, hence the classical ion-exchange concept based on exchange equilibrium constants and separation factors (Vermeulen et al., 1973; Shallcross et al., 1988) can be applied to this case. For the ion-exchange reaction

$$
b \mathrm{~A}^{+a}+a B^{+b}=\mathrm{bA}^{+a}+a \mathrm{~B}^{+b}
$$

the equilibrium constant $K_{\mathrm{AB}}$ and the separation factor $r_{\mathrm{AB}}$ are defined as

$$
\begin{gathered}
K_{\mathrm{AB}}=\frac{q_{\mathrm{A}}^{b} C_{\mathrm{Bf}}^{a}}{C_{\mathrm{Af}}^{b} q_{\mathrm{B}}^{a}}=\frac{y_{\mathrm{A}}^{b} x_{\mathrm{B}}^{a}}{x_{\mathrm{A}}^{b} y_{\mathrm{B}}^{a}} \cdot \frac{C_{0}^{a-b}}{Q^{a-b}} \\
r_{\mathrm{AB}}=\frac{y_{a} x_{\mathrm{B}}}{x_{a} y_{b}}
\end{gathered}
$$

for the case of ideal behavior of the exchanging species in both of the phases. As can be seen from equation (6a), the total normality $C_{0}$ of the solution affects the equilibrium of a heterovalent exchange, i.e. when $a \neq b$, but it does not affect the equilibrium when the valence of the exchanging species is the same, i.e. $a=b$. Consequently, the ion-exchange isotherms of a species in a binary heterovalent system vary in shape depending on the total normality of the solution (Selke, 1956).

Equilibrium relationships. The term "equilibrium sorption isotherm" is commonly used in biosorption to refer to a curve connecting equilibrium metal uptakes plotted against the final concentrations of the metal. Typically, biosorption equilibrium data are obtained under the same $\mathrm{pH}$. However, this is not the case in ion exchange where the sorption isotherm represents data points obtained at a constant normality of the solution. Furthermore, in compliance with the established convention, ion-exchange isotherms for binary systems usually display dimensionless uptakes as function of dimensionless concentrations for the species of interest.

$$
\frac{q_{\mathrm{M}}}{Q}=\mathrm{f}\left(\frac{C_{\mathrm{ML}}}{C_{0}}\right)
$$

Connection between equilibrium and dynamic sorption in columns. Unlike the biosorption isotherm, the ion-exchange isotherm depicts an equilibrium situation which is relevant to the case of the biosorption of $\mathrm{Cu}$ in a fixed-bed adsorber in which the concentration of the species released from the sorbent increases monotonically in the direction of the flow. In fact, the ion-exchange isotherm represents the "equilibrium line" which is, together with the "operating line", sometimes used for assessing design and performance of fixed-bed adsorbers (Michaels, 1952; Liberti and Passino, 1982). According to the shape of the ion-exchange isotherm, the equilibrium is classified as (a) "favorable" when the isotherm is concave, (b) "linear" when the isotherm is linear or (c) "unfavorable" when the isotherm is convex.

It is known that the "favorable isotherm" leads to the development of a self-sharpening exchange zone in the fixed-bed adsorber, whereas the "unfavorable isotherm" gives rise to a broadening dynamic sorption zone (Helfferich, 1962; Coulson and Richardson, 1991). As an alternative to ion-exchange isotherms, tables of values of separation factors for the compositions existing in an adsorber can be used to represent the equilibrium for the purpose of computer simulation of the fixed bed (Tan and Spinner, 1994).

\section{Fixed-bed model}

Two relatively recent studies of biosorption in fixed-bed columns employed models originally developed for the sorption of a single solute (Volesky and Prasetyo, 1994) and for a multicomponent mixture (Trujillo et al., 1991) on activated carbon. In the case of biosorption of $\mathrm{Cu}$ by algal biomass, however, an ion-exchange model rather than a model of activated carbon sorption should be used, since a considerable amount of ions is being released from the biosorbent in exchange for sorbed $\mathrm{Cu}$. The approaches used for modeling ion exchange in fixed beds by Hiester and Vermeulen (1952) for single solute and by Helfferich (1967) and Klein et al. (1967) for multicomponent mixtures are restricted to systems with constant separation factors and/or to infinitely long fixed beds for which the assumption of a local equilibrium is valid. The most universal approach seems to be the one adopted by Tan and Spinner (Tan and Spinner, 1994) who numerically solved a mixed system of partial differential, ordinary differential and algebraic equations describing the dynamics of multicomponent ion exchange in a fixed bed. In the present work, the model of Tan and Spinner (1994) has been adopted with the following modifications. First, the application of the model in the present work is restricted to binary systems, i.e. single solute ion exchange, which allows the testing of the approach for the case of biosorption while reducing the number of equations to a minimum. Second, a term is added to the differential molar balance equation, in order to account for axial dispersion of the fluid in the packed bed. Assuming isothermal conditions and constant physical properties for the feed solution, the differential molar balance for a sorbing species $M$ is

$$
\frac{\partial C_{M}}{\partial z}-\frac{1}{P e_{\mathrm{c}}} \frac{\partial^{2} C_{\mathrm{M}}}{\partial z^{2}}+\frac{\partial C_{\mathrm{M}}}{\partial t}+D_{\mathrm{gM}} \frac{\partial q_{\mathrm{M}}}{\partial t}=0
$$

The sorption rate equation can be written as 


$$
\frac{\partial q_{\mathrm{M}}}{\partial t}=S h_{\mathrm{M}}\left(q_{\mathrm{M}}^{*}-q_{\mathrm{M}}\right)
$$

assuming a linear driving force for the sorption process and combined film and intraparticle masstransfer resistance. The equilibrium relationship for a metal species represented by equations (2) and (3) can be written schematically for a general counterion, i.e. either proton or metal, as

$$
q_{\mathrm{M}}^{*}=\mathrm{f}\left(C_{\mathrm{M}}, C_{\mathrm{CNT}}\right)
$$

and the electroneutrality equation for binary systems is

$$
\frac{C_{\mathrm{M} 0}-C_{\mathrm{M}}}{M_{\mathrm{WM}}}=v \frac{C_{\mathrm{CNTO}}-C_{\mathrm{CNT}}}{M_{\mathrm{WCNT}}}
$$

To obtain equations (8)-(11), the original set of equations was transcribed with dimensionless variables using the following transformations of the variables:

$$
\begin{gathered}
C_{\mathrm{M}}=\frac{C_{\mathrm{ML}}}{C_{0}} \quad q_{\mathrm{M}}=\frac{q_{\mathrm{MS}}}{Q} \\
t=\frac{\tau \nu}{L_{0}} \quad z=\frac{l}{L_{0}}
\end{gathered}
$$

and yielding the following dimensionless groups

$$
D_{\mathrm{gM}}=\frac{\rho_{\mathrm{b}} Q}{C_{0} \epsilon} \quad S h_{\mathrm{M}}=\frac{K_{\mathrm{m}} L_{0}}{v} \quad P e_{\mathrm{c}}=\frac{L_{0} v}{D_{\mathrm{z}}}
$$

The initial and boundary conditions pertaining to the situations under question are specified as follows:

$$
\begin{gathered}
t=0 \quad l=\left(0, L_{0}\right) \quad C_{\mathrm{M}}=0 \\
t>0 \quad l=0 \quad C_{\mathrm{M}}=C_{\mathrm{M} 0}+\frac{1}{P e_{\mathrm{c}}} \frac{\partial C_{\mathrm{M}}}{\partial z} \\
t>0 \quad l=L_{0} \quad \frac{\partial C_{\mathrm{M}}}{\partial z}=0
\end{gathered}
$$

The system of equations (8)-(11) was solved numerically by using Galerkin finite-element method (Fletcher, 1984), combined with the implicit Euler method for time integration. Linear basis functions were used for space discretization of both concentrations $C$ and uptakes $q$. Two different discretizations dividing the column into 30 and 50 elements, respectively, were used to ensure that the model solution was mesh independent. Both discretizations gave results which were identical to the fourth significant digit.

Fitting the equilibrium model and calculation of ion-exchange isotherms

In this work, equilibrium data sets for $\mathrm{Cu} / \mathrm{H}$ and $\mathrm{Cu} / \mathrm{Ca}$ sorption systems, where the first element indicates the sorbing species and the second element specifies the ionic form of the biomass, provided the experimental basis for the fitting of the biosorption model. Using the binary systems data, the model equilibrium constants could be fitted in a step-by-step fashion as follows. First, the concentration of binding sites $C_{1}$ was determined from the uptake experiments carried out separately with $\mathrm{Ca}$ and $\mathrm{Cu}$ on $\mathrm{H}$-biomass at controlled $\mathrm{pH}$. In these experiments, the final concentration of the metals was approximately $C_{\mathrm{CCu}}=4 \mathrm{mM}$ and $C_{\mathrm{rCa}}=50 \mathrm{mM}$, corresponding to the upper limits of the respective concentration ranges for the two metals shown in Table 3 . The equilibrium conditions reached in these experiments were assumed to be such that $\left(K_{\mathrm{M}} C_{\mathrm{FM}}\right)^{0.5} \gg 1+K_{\mathrm{H}} C_{\mathrm{FH}}$ was true in equation (2), yielding $q_{\mathrm{M}}=0.5 M_{\mathrm{wM}} C_{1}$; this assumption was verified by a back-substitution, described later. Second, the constants $K_{\mathrm{H}}$ and $K_{\mathrm{Cu}}$ were obtained by minimizing the objective function $F_{\mathrm{Cu}}$ represented by equation (4), on the data set $\mathrm{Cu} / \mathrm{H}$. Third, the constant $K_{\mathrm{Ca}}$ was determined by minimization of $F_{\mathrm{Ca}}$, on the data set $\mathrm{Cu} / \mathrm{Ca}$. The computer program MATLAB (Version 4.0) was used for minimization of $F_{\mathrm{C}_{u}}$ and $F_{\mathrm{Ca}}$.

Once the parameters were fitted, the biosorption model was used to calculate ion-exchange isotherms as follows. First, the normality of a binary mixture $C_{0}$ was fixed and the uptake $Q$, as the concentration of the sorbing species $C_{0}$, was calculated from equation (2) or (3). Second, a series of liquid-phase compositions was selected in such a way that the dimensionless concentration $C / C_{0}$ of one of the species covers the interval of interest. And finally, a series of dimensionless uptakes corresponding to the series of compositions was calculated using equations (2), (3) and (7).

\section{Fitting and use of the fixed-bed model}

The dimensionless groups $S h, D_{\mathrm{g}}$ and $P e$, together with the equilibrium parameters for a given binary system, represent the parameters of the fixed-bed model. However, since the equilibrium parameters can be determined from batch equilibrium studies, the values of $C_{0}, v, L_{0}$ and $\rho_{\mathrm{b}}$ are usually known and $Q$ can be calculated from equations (2 and 3 ), the only remaining unknowns in the model are $K_{\mathrm{IM}}, D_{\text {z }}$ and $\epsilon$. The values of the three unknowns $K_{\mathrm{r}}, D_{\text {: }}$ and $\epsilon$ have to be determined simultaneously by fitting the fixed-bed model to an experimental breakthrough curve.

The value of an overall mass-transfer coefficient for a given species generally depends on the flowrate, the axial dispersion coefficient and the values of the diffusivities of the species in the liquid and solid phases. The diffusion coefficients of $\mathrm{Cu}^{2+}$ and $\mathrm{Ca}^{2+}$ in diluted aqueous solutions are $0.714 \times 10^{-9}$ and $0.792 \times 10^{-9} \mathrm{~m}^{2} / \mathrm{s}$, respectively, as tabulated by Mills and Lobo (1989). The diffusivity of $\mathrm{Cu}$ in alginate gels measured independently by Jang $e t$ al . (1990) and Chen et al. (1993) was determined to lie in the range of $1-1.4 \times 10^{-9} \mathrm{~m}^{2} / \mathrm{s}$. Chen concluded that, for small species such as ions, the values of diffusivities in alginate gels and in water are approximately the same. Consequently, a reasonable assumption can be made that one value of $K_{\mathrm{m}}$ can be applied to both $\mathrm{Cu}$ and $\mathrm{Ca}$ ions sorbing onto Sargassum biomass in a 


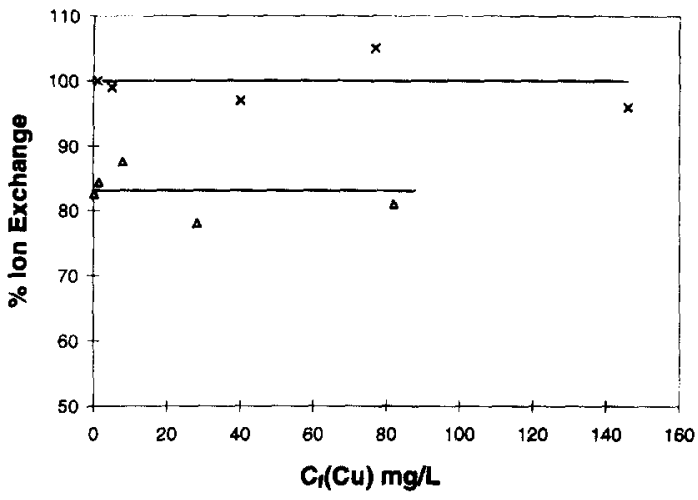

Fig. 1. Percentage of ion exchange in biosorption of $\mathrm{Cu}$ by $\mathrm{H}-$ and $\mathrm{Ca}$-preloaded biomass of Sargassum fuitans:

$$
\begin{aligned}
& \frac{\text { (equivalents of counter ion released) } \times 100 \%}{\text { equivalents of } \mathrm{Cu} \text { sorbed }} \\
& (\times) \text { counterion } \mathrm{Ca}^{2+} ;(\Delta) \text { counterion } \mathrm{H}^{+} .
\end{aligned}
$$

column under the same flowrate. It should be noted, however, that the application of the assumption that $K_{\mathrm{fCu}}=K_{\mathrm{fCa}}$ to multi-metal systems may hide masstransfer effects on the breakthrough curves as described by Tan and Spinner (1994).

\section{RESULTS}

Equilibrium biosorption of $\mathrm{Cu}$ as an ion-exchange process

To demonstrate the role of ion exchange in the biosorption of $\mathrm{Cu}$ by $S$. fluitans, and to justify the use of ion-exchange models to treat and interpret the biosorption data, the balance of equivalents of species sorbed onto and released from the biomass during both batch equilibrium and dynamic column experiments was calculated. Figure 1 shows that during the batch equilibrium experiments more than $80 \%$ of equivalents of $\mathrm{Cu}$ uptaken by the biomass replaced $\mathrm{Ca}$ and $\mathrm{H}$ in the biomass structure. Figure 2 demonstrates that the exchange between $\mathrm{Ca}$ and $\mathrm{Cu}$

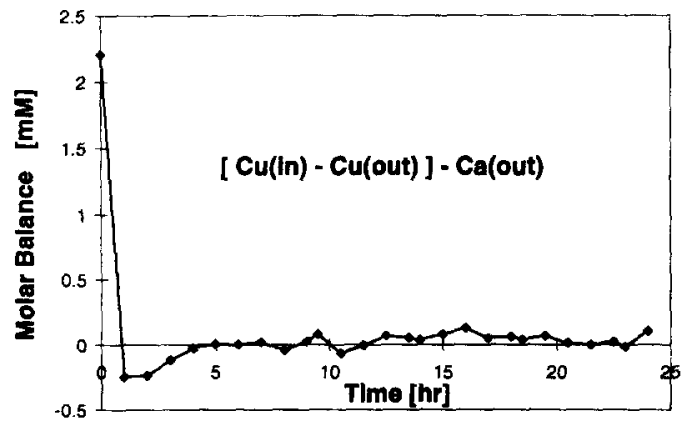

Fig. 2. Molar balance of ions over a sorption column removing $\mathrm{Cu}$ :

(mmols of ions in inlet) - (mmols of ions in outlet)

Sargassum fluitans biomass preloaded with $\mathrm{Ca}$ at $\mathrm{pH}=4.5$; column length $20 \mathrm{~cm} ; \mathrm{C}(\mathrm{Cu})$ in feed $2.3 \mathrm{~mm}$; flowrate $7.5 \mathrm{ml} / \mathrm{min}$

\begin{tabular}{|c|c|c|c|}
\hline Pretreating solution & $\begin{array}{c}\text { Weight loss } \\
(\%)\end{array}$ & $\begin{array}{c}C(\mathrm{Cu}) \\
\text { (mg/liter) }\end{array}$ & $\begin{array}{l}4(\mathrm{Cu}) \\
\text { (mg g g) }\end{array}$ \\
\hline \multicolumn{4}{|l|}{$\mathrm{CaCl}_{2}$} \\
\hline $1 \%(w)$ & 24 & 185 & 75 \\
\hline \multicolumn{4}{|l|}{$\mathrm{HCl}$} \\
\hline $0.1 \mathrm{M}$ & 44 & 180 & 76 \\
\hline \multicolumn{4}{|l|}{$\mathrm{HCl}$} \\
\hline $1 \mathrm{M}$ & 45 & 192 & 72 \\
\hline \multicolumn{4}{|l|}{$\mathrm{H}_{2} \mathrm{SO}_{4}$} \\
\hline $0.05 \mathrm{M}$ & 40 & 184 & 66 \\
\hline \multicolumn{4}{|l|}{$\mathrm{H}_{2} \mathrm{SO}_{4}$} \\
\hline $0.5 \mathrm{M}$ & 41 & 214 & 64 \\
\hline \multicolumn{4}{|l|}{$\mathrm{CaCl}_{2}$ followed by } \\
\hline $\mathrm{HCl} 0.1 \mathrm{M}$ & 32 & 180 & 71 \\
\hline
\end{tabular}

Table 1. Biomass pretreatment

ions in a packed-bed column can be considered quantitatively stoichiometric within the range of experimental error and sensitivity of the analytical techniques used. The concentration of $\mathrm{Cu}$ in the feed was $2.3 \mathrm{~mm}$ and the biomass in the column was pretreated with $1 \% \mathrm{CaCl}_{2}$.

The results of the biomass pretreatment are summarized in Table 1. The values of uptakes displayed in the fourth column of Table 1 are related to the dry weight of pretreated biomass.

Fitting of biosorption model. Three experimental data sets were obtained for the three binary systems, $\mathrm{C} / \mathrm{H}, \mathrm{Cu} / \mathrm{Ca}$ and $\mathrm{Ca} / \mathrm{H}$. The biosorption model represented by equations (1)-(3) was fitted to the experimental data as described earlier. Table 2 lists the values of all the model parameters which had to be determined. The $C_{t}$ value of $2.3 \mathrm{meq} / \mathrm{g}$ corresponding to a $\mathrm{Cu}$ uptake of $73 \mathrm{mg} / \mathrm{g}$ agrees well with the $C_{t}$ value of $2.05 \mathrm{meq} / \mathrm{g}$ determined by Schiewer and Volesky (1995b) and the $2.25 \mathrm{meq} / \mathrm{g}$ determined by Fourest and Volesky (1996). Furthermore, assuming that alginate comprises approximately $45 \%$ of $S$. fluitans biomass dry weight (Fourest and Volesky, 1996), the $C_{t}$ of $2.3 \mathrm{meq} / \mathrm{g}$ agrees reasonably well with the value $4.36 \mathrm{meq} / \mathrm{g}$ determined by Jang et $\mathrm{al}$. (1995a) for pure $\mathrm{Na}$-alginate. The data set $\mathrm{Ca} / \mathrm{H}$ was not used for fitting; therefore, the agreement between model predictions and the data from the $\mathrm{Ca} / \mathrm{H}$ data set can serve to validate the application of the biosorption model. The consistency of the model can be verified by substituting the value of $K_{\mathrm{Cu}}$ determined by fitting and the values of $q_{\mathrm{Cu}}$ and $C_{\mathrm{fCu}}$ determined during the metal uptake experiment $\left(C_{\mathrm{fCu}}=4 \mathrm{~mm}\right.$ and $q_{\mathrm{Cu}}=73 \mathrm{mg} / \mathrm{g}$ ) into equation (2) and then calculating $C_{1}$ from the same equation. The $C_{4}$ value of $2.093 \mathrm{meq} / \mathrm{g}$ thus obtained is close to the value of $2.3 \mathrm{meq} / \mathrm{g}$ and is within the acceptable range of experimental and modeling errors commonly encountered in biosorption (Schiewer and Volesky, 1995a, b). This result supports the consistency of the model.

Table 2. Biosorption model parameters

\begin{tabular}{lcc}
\hline Parameters & Units & Fitted value \\
\hline$C_{1}$ & meq $/ g$ & 2.3 \\
$K_{\mathrm{Cu}}$ & liter $/ \mathrm{mol}$ & 32255 \\
$K_{\mathrm{H}}$ & liter $/ \mathrm{mol}$ & 4624 \\
$K_{\mathrm{Cu}}$ & liter $/ \mathrm{mol}$ & $503 !$ \\
\hline
\end{tabular}


Table 3. Results of minimization

\begin{tabular}{lcccc}
\hline Binary system & $\begin{array}{c}\text { Concentration range } \\
\text { of sorbing species } \\
\text { (mg/liter) }\end{array}$ & Value of $F_{\mathrm{M}}$ & $\begin{array}{c}\text { Percentage of data within } \\
12 \% \text { error band } \\
\text { around the fit }\end{array}$ & $\begin{array}{c}\text { Percentage of data within } \\
5 \% \text { error band } \\
\text { around the fit }\end{array}$ \\
\hline $\mathrm{Cu} / \mathrm{H}$ & $2-280$ & 0.022 & 100 & 70 \\
$\mathrm{Cu} / \mathrm{Ca}$ & $5-220$ & 0.152 & 86 & 43 \\
$\mathrm{Ca} / \mathrm{H}$ & $2-2000$ & 0.090 & 71 & 57 \\
\hline
\end{tabular}

Table 3 displays values of some of the quantities serving as measures of the goodness of fit. As can be seen from the values in the tables, the model fits the experimental data relatively well.

lon-exchange isotherms. Figure 3 shows ion-exchange isotherms for the $\mathrm{Cu} / \mathrm{H}$ system calculated for the normality of the solution $C_{0}=1,2,4$ and $6 \mathrm{meq} /$ liter. Figures 4 and 5 show similar isoutherms obtained for $\mathrm{Cu} / \mathrm{Ca}$ and $\mathrm{Ca} / \mathrm{H}$ systems, respectively. Although the biosorption model can be used for modeling both adsorption and desorption (Schiewer and Volesky, 1995b), the desorption isotherms presented in Figs 6 and 7, calculated for the systems $\mathrm{Ca} / \mathrm{Cu}$ and $\mathrm{H} / \mathrm{Cu}$, respectively, may not be accurate due to the extrapolation of $C_{0}$ beyond the values of normalities of the solutions for which the model was originally fitted.

\section{Dynamic biosorption in the fixed bed}

To assess the effect of an ionic form of the biomass on the performance of a biosorption column, three breakthroughs of $\mathrm{Cu}$ were measured on the biomass packing with height equal to $20 \mathrm{~cm}$ which was (a) protonated, (b) loaded with $\mathrm{Ca}$ at $\mathrm{pH} 2.5$ and (c) loaded with $\mathrm{Ca}$ at $\mathrm{pH}$ 3.5. Cu was stripped from the bed with $\mathrm{HCl}$ and the Ca-loading was carried out in between the sorption experiments as described earlier. Figure 8 displays the three breakthrough curves which exhibit a sharpening trend following the increased content of $\mathrm{Ca}$ in the packing. To demonstrate the effect of the pretreatment of the biomass on the performance of a fixed bed, another sequential sorption experiment was conducted in a column with the height of the packing $L=40 \mathrm{~cm}$. The first $\mathrm{Cu}$-sorption was performed on $\mathrm{CaCl}_{2}$ pretreated biomass. The second and the third sorptions were performed on $\mathrm{H}$-biomass, i.e. immediately following the desorption of $\mathrm{Cu}$ from the column with $\mathrm{HCl}$. The breakthrough curves in Fig. 9 show that the capacity of the column decreased by approximately $30 \%$ after the first cycle but remained almost unchanged during the second and the third cycle.

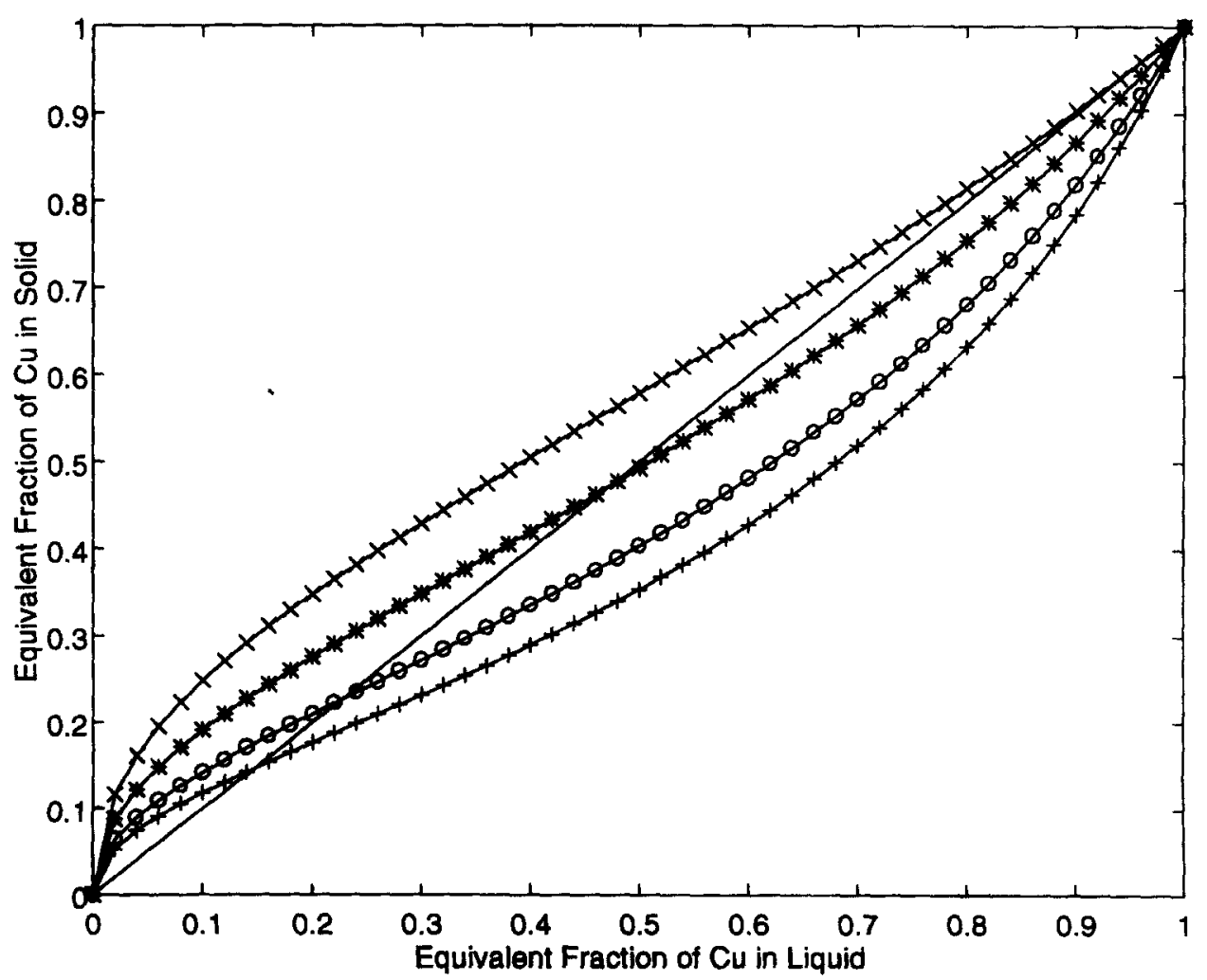

Fig. 3. Calculated $\mathrm{Cu}^{2+}$ sorption isotherms using H-Sargassum biomass: $C_{0}(+) 6,(\mathrm{O}) 4,\left(^{*}\right) 2$ and $(\times)$ $1 \mathrm{meq} / \mathrm{liter}$. 


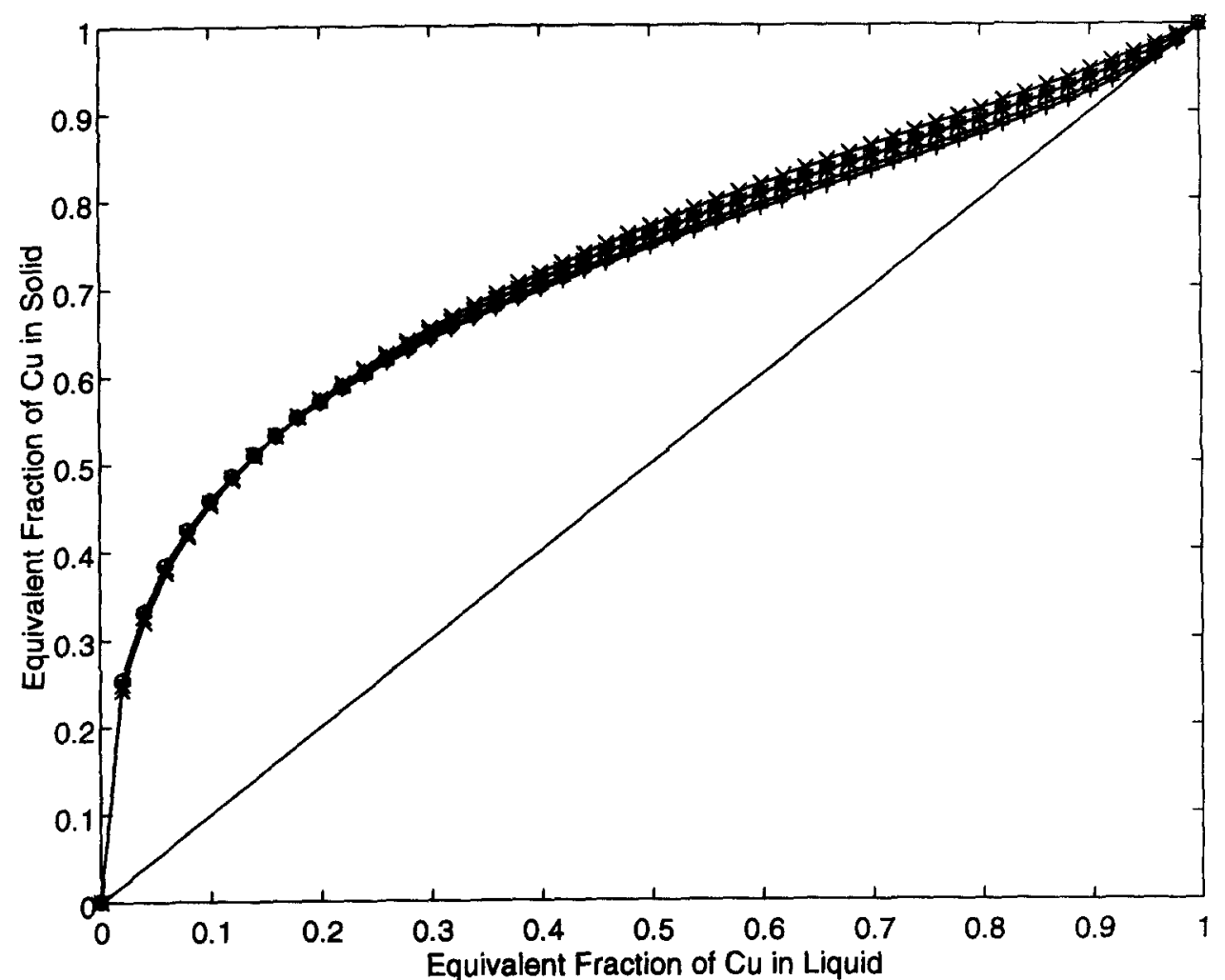

Fig. 4. Calculated $\mathrm{Cu}^{2+}$ sorption isotherms using Ca-Sargassum biomass: $C_{11}(+) 6,(\mathrm{O}) 4,\left({ }^{*}\right) 2$ and $(\times)$ $1 \mathrm{meq} / \mathrm{liter}$.

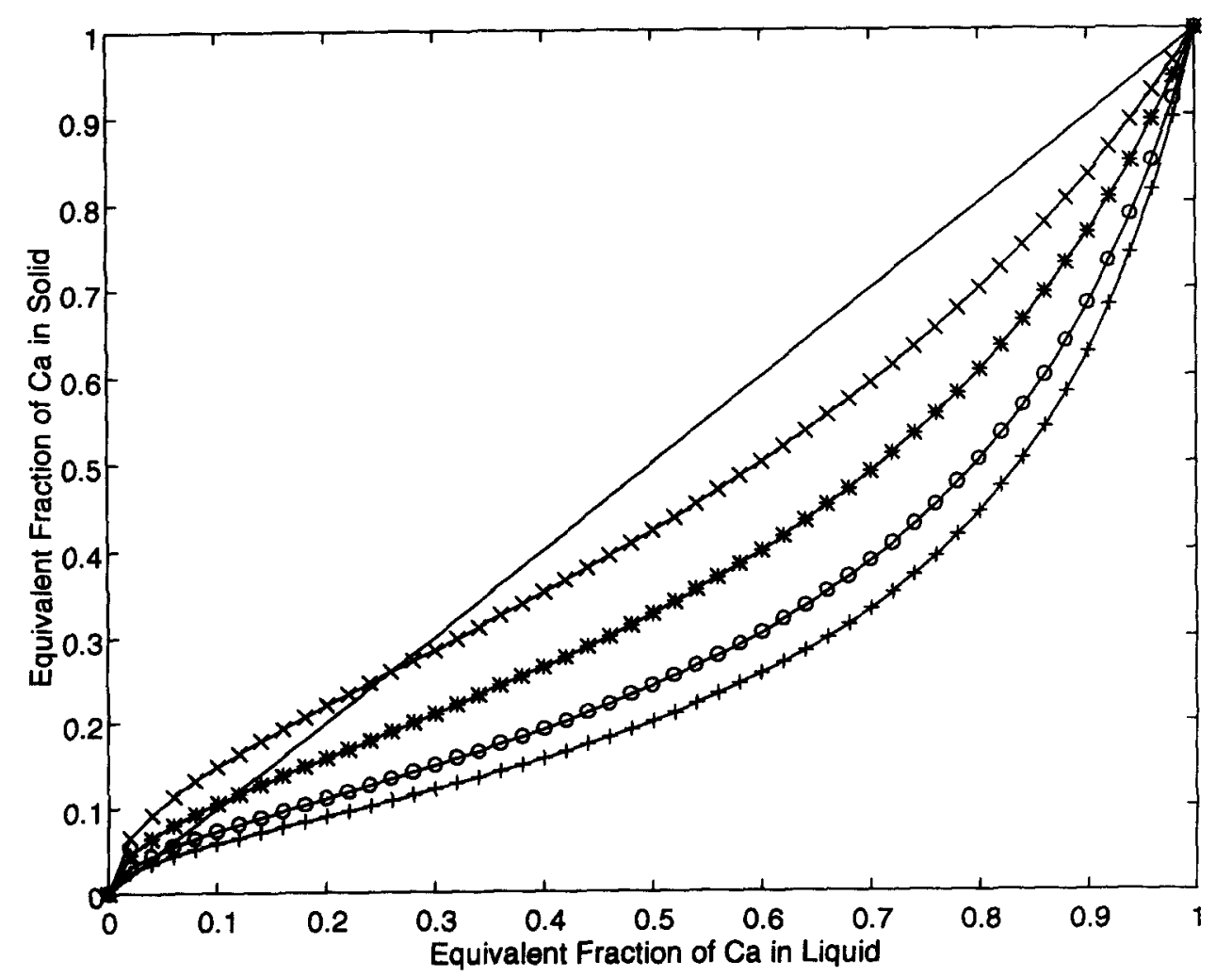

Fig. 5. Calculated $\mathrm{Ca}^{2+}$ sorption isotherms using H-Sargassum biomass: $C_{0}(+) 6,(O) 4,\left(^{*}\right) 2$ and $(\times)$ $1 \mathrm{meq} /$ liter. 


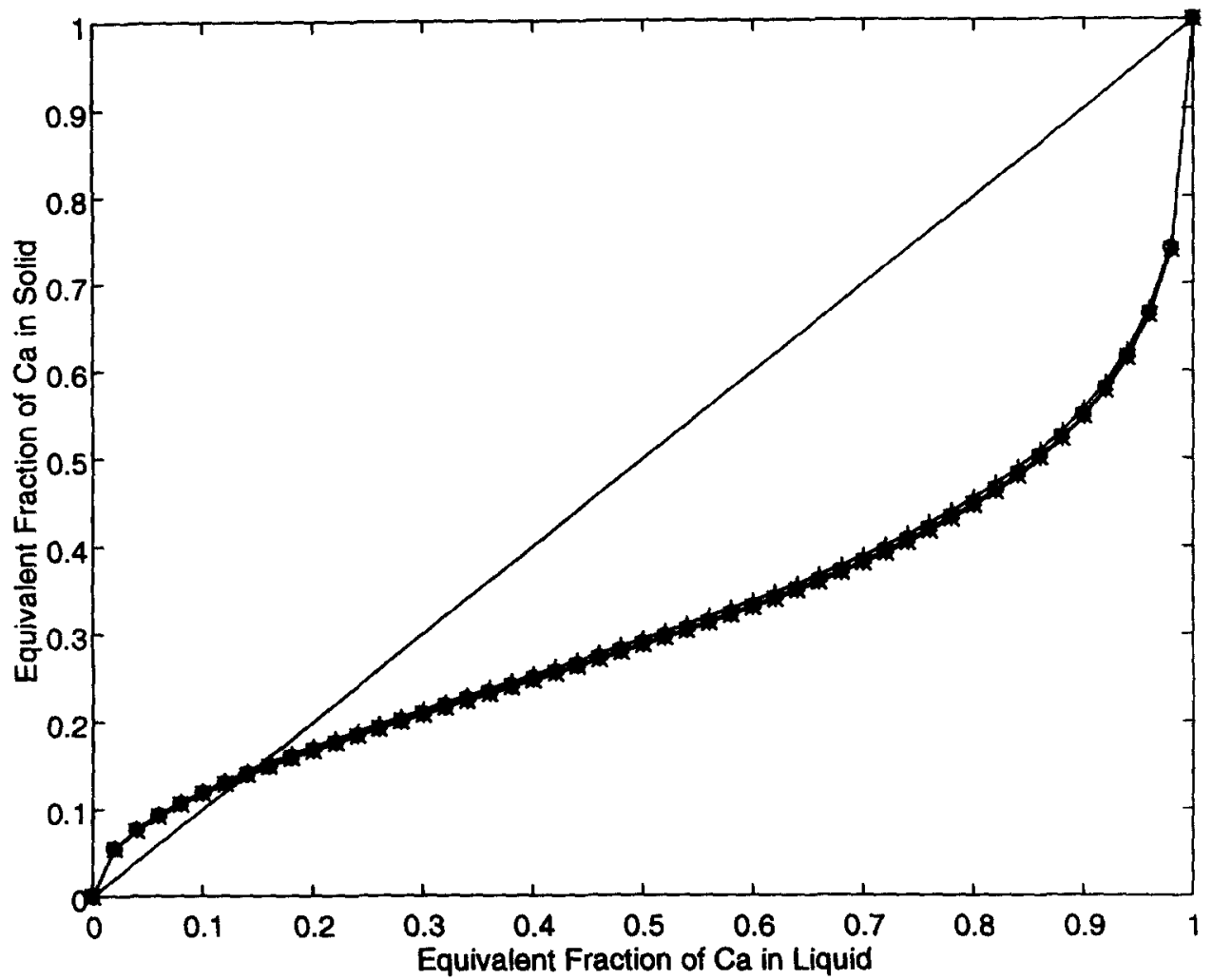

Fig. 6. Calculated desorption isotherms: $\mathrm{Ca}^{2+}$ desorbing $\mathrm{Cu}^{2+}$ from Sargassum biomass: $\mathrm{C}_{0}(+) 0.1,(\mathrm{O})$ 0.5 and $\left({ }^{*}\right) 1 \mathrm{M}$.

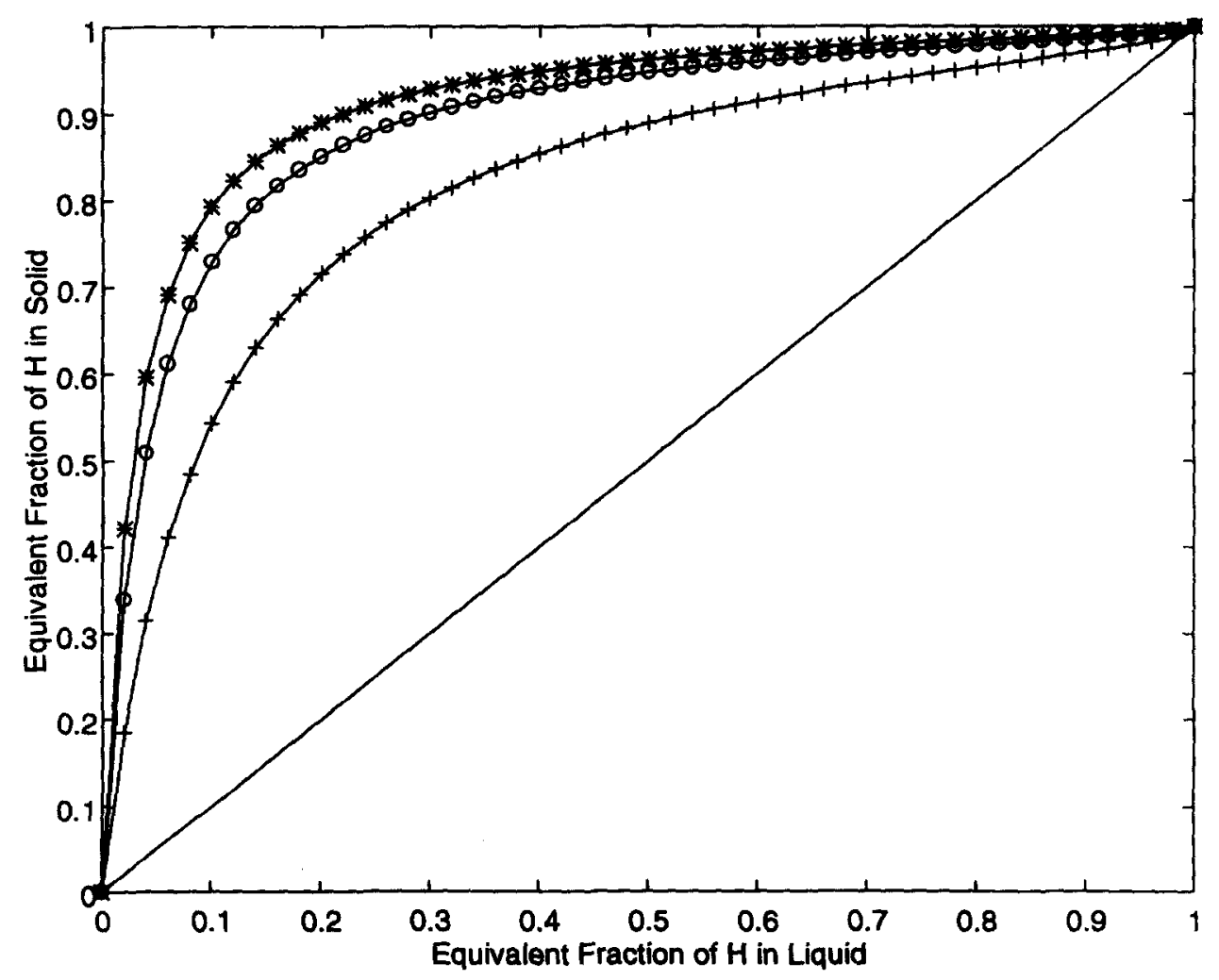

Fig. 7. Calculated desorption isotherms: $\mathrm{H}^{+}$desorbing $\mathrm{Cu}^{2+}$ from Sargassum biomass: $C_{0}(+) 0.1,(\bigcirc)$ 0.5 and $\left(^{*}\right) 1 \mathrm{M}$. 


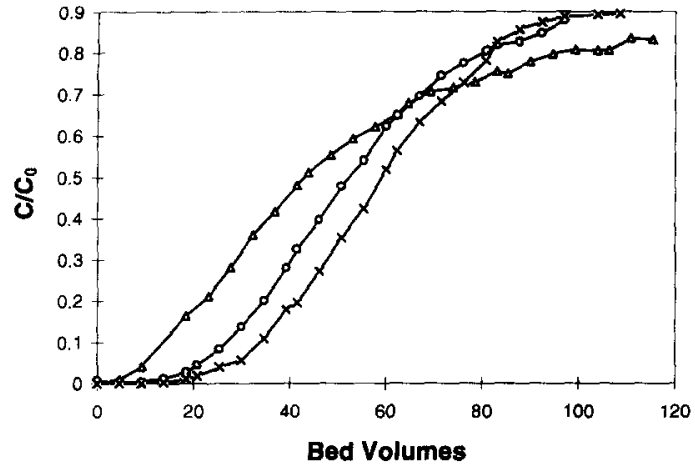

Fig. 8. Biosorption of $\mathrm{Cu}$ on pretreated Sargassum biomass. Demonstration of the 'sharpening' effect on column breakthrough curves. Column length $20 \mathrm{~cm} ; \mathrm{C}(\mathrm{Cu})$ in feed $2.3 \mathrm{~mm}$; flowrate $7.5 \mathrm{ml} / \mathrm{min}$. Biomass: $(\triangle)$ protonated; $(O)$ loaded with $\mathrm{Ca}$ at $\mathrm{pH} 2.5 ;(\times)$ loaded with $\mathrm{Ca}$ at $\mathrm{pH} 3.5$.

Fitting of fixed-bed column model. The values of $K_{\mathrm{fM}}, D_{2}$ and $\epsilon$ were determined simultaneously by fitting the model to the experimental breakthrough curve obtained for $\mathrm{Cu}$ on 20 -cm-long H-biomass packing. The fitted values of $K_{\mathrm{fm}}, D_{\mathrm{z}}$ and $\epsilon$ were $0.006 \mathrm{~min}^{-1}, 80 \mathrm{~cm}^{2} / \mathrm{min}$, and 0.72 , respectively. Next, the model prediction of the breakthrough of $\mathrm{Cu}$ on $\mathrm{H}$-biomass in a $40-\mathrm{cm}$-long column was generated and compared with the second sorption breakthrough shown in Fig. 9. The fit for the short bed and the prediction for the long bed are plotted together with the corresponding experimental breakthrough curves in Fig. 10.

Elution of $\mathrm{Cu}$ from fixed bed. To assess the performance of $\mathrm{HCl}$ and $\mathrm{CaCl}_{2}$ as eluents for $\mathrm{Cu}$, two desorption experiments were designed as follows. In the first experiment, the solution of acid was pumped into the column and the samples of the effluent were collected over time. In the second experiment, $\mathrm{CaCl}_{2}$ at pH 6 was initially applied to the column to strip $\mathrm{Cu}$ from the bed until the concentration of $\mathrm{Cu}$ in the column effluent decreased to below $30 \mathrm{mg} / \mathrm{liter}$, then acid was introduced into the column to desorb the rest of the $\mathrm{Cu}$. Figure 11 shows the $\mathrm{Cu}$ elution curves obtained from the two experiments. The area under

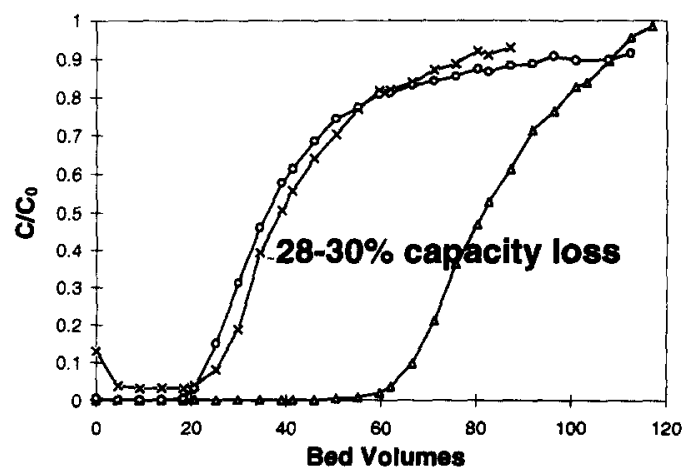

Fig. 9. Loss of sorption column capacity in consecutive sorption/desorption cycles with $\mathrm{CaCl}_{2}$-pretreated biomass: $(\triangle)$ 1st cycle Ca-biomass; $(O)$ 2nd cycle H-biomass; $(x)$ 3rd cycle H-biomass; column length $40 \mathrm{~cm} ; \mathrm{C}(\mathrm{Cu})$ in feed $2.8 \mathrm{~mm}$; flowrate $7.5 \mathrm{ml} / \mathrm{min}$.

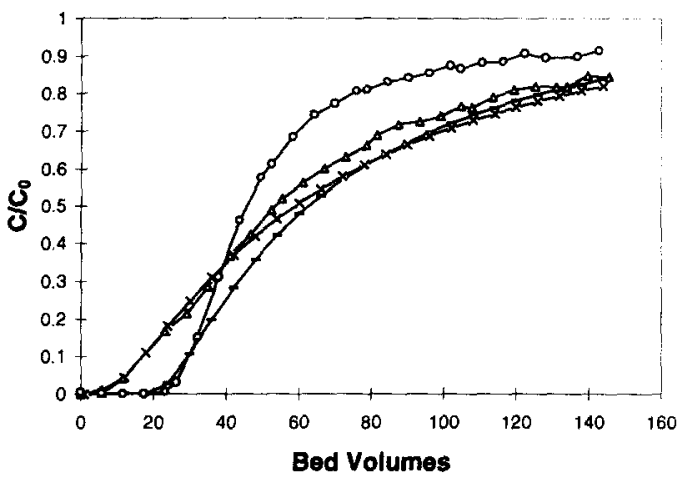

Fig. 10. Experimental and model $\mathrm{Cu}$ breakthrough curves for H-biomass of Sargassum: $(\triangle)$ experiment $L=20 \mathrm{~cm}$; (×) model $L=20 \mathrm{~cm}$; (O) experiment $L=40 \mathrm{~cm}$; (-) model $L=40 \mathrm{~cm}$; flowrate $7.5 \mathrm{ml} / \mathrm{min}$.

the concentration curve obtained from the experiment in which $\mathrm{CaCl}_{2}$ and $\mathrm{HCl}$ were applied in a sequence was calculated by integration. The area under the peak corresponding to the elution of $\mathrm{Cu}$ by $\mathrm{CaCl}_{2}$, i.e. up to 18 bed volumes mark, represents approximately $70 \%$ of the total area under the elution curve. Moreover, it can be seen from Fig. 11 that, when $\mathrm{HCl}$ is used as an eluent, $100 \%$ of $\mathrm{Cu}$ is desorbed within a time corresponding to 7 bed volumes.

$\mathrm{Ca} / \mathrm{H}$ regeneration in fixed bed. This was conducted, as described in the section on Ca-loading, in the $20-\mathrm{cm}$-long column with the $\mathrm{pH}$ controller set to maintain $\mathrm{pH}=6$. Since, under the given conditions, only a small fraction of $\mathrm{Ca}$ fed into the column adsorbed on the packing, the concentration of $\mathrm{Ca}^{2+}$ in the column effluent jumped to $C_{\mathrm{Cal}}=0.95$ $C_{\mathrm{CaL}}$ (feed) almost instantaneously. Therefore, the evolution of $\mathrm{pH}$ in the outlet from the fixed bed rather than a breakthrough of $\mathrm{Ca}$ should be used to describe the kinetics of the regeneration process. The experimental $\mathrm{pH}$ curve and the model prediction for $K_{\mathrm{IM}}=0.006 \mathrm{~min}^{-1}$ are shown in Fig. 12. Figure 13 shows the achieved regeneration as a function of the number of bed volumes as it is predicted by the model for four different concentrations of the $\mathrm{Ca}$ in the fresh

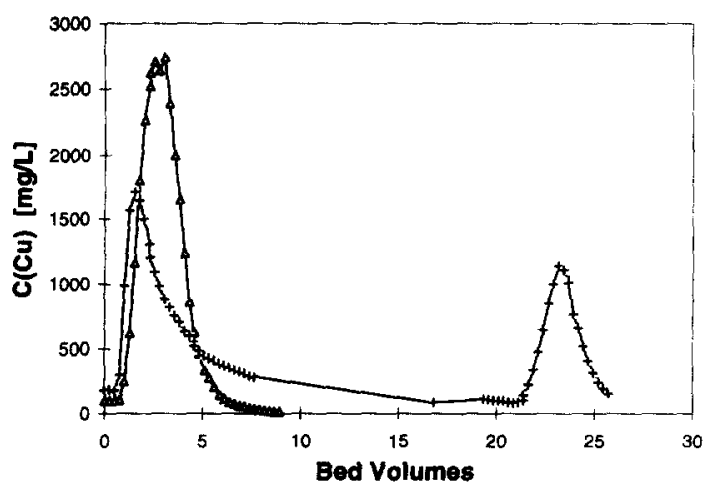

Fig. 11. Desorption of $\mathrm{Cu}$ from a biosorbent fixed bed of Sargassum using eluants: $(+) 1 \%$ (w) aq. $\left.\mathrm{CaCl}_{2} ; \triangle\right) 0.1 \mathrm{M}$ $\mathrm{HCl}$; column length $40 \mathrm{~cm}$; flowrate $10 \mathrm{ml} / \mathrm{min}$. 


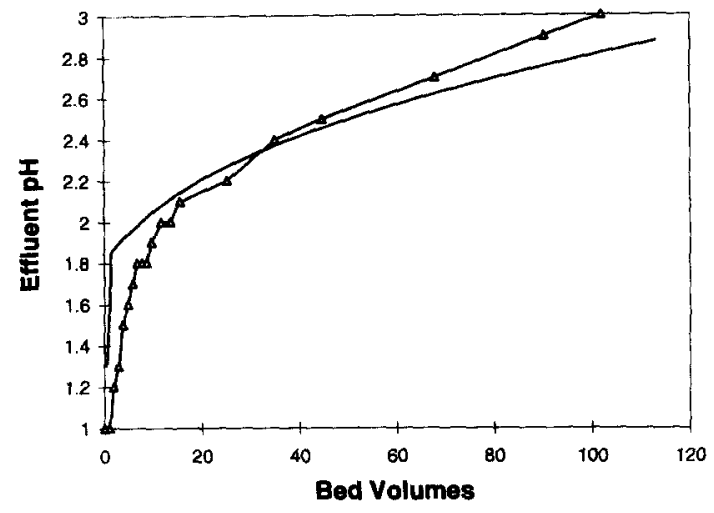

Fig. 12. Dynamics of $\mathrm{Ca} / \mathrm{H}$ regeneration in a fixed-bed column of Sargassum biomass: $(\triangle)$ experiment; $(-)$ model; column length $20 \mathrm{~cm}$; flowrate $7.5 \mathrm{ml} / \mathrm{min}$.

regenerant. The regeneration curves plotted in Fig. 13 were calculated as follows. The computer program calculates a spatial profile of dimensionless $\mathrm{Ca}$ uptakes across the bed during each time step. As the simulation marches forward in time, some of the uptake profiles are integrated and saved in a datafile together with a corresponding value of dimensionless time. Consequently, each datapoint in Fig. 13 represents one integrated uptake profile plotted against the given time.

\section{DISCUSSION}

As can be seen from Figs 1 and 2, biosorption of $\mathrm{Cu}$ by Sargassum biomass in both $\mathrm{H}$-form and $\mathrm{Ca}-$ form can be viewed as an ion-exchange process. The fact that the exchange between $\mathrm{Cu}$ and $\mathrm{H}$ appears less quantitative may be due to a relatively low accuracy in the determining the $H$ ion concentration as compared to the accuracy of determining the $\mathrm{Cu}$ concentration and/or due to the fact that the mechanism of binding of $\mathrm{Cu}$ by the $\mathrm{H}$-biomass is more complex than just a simple ion

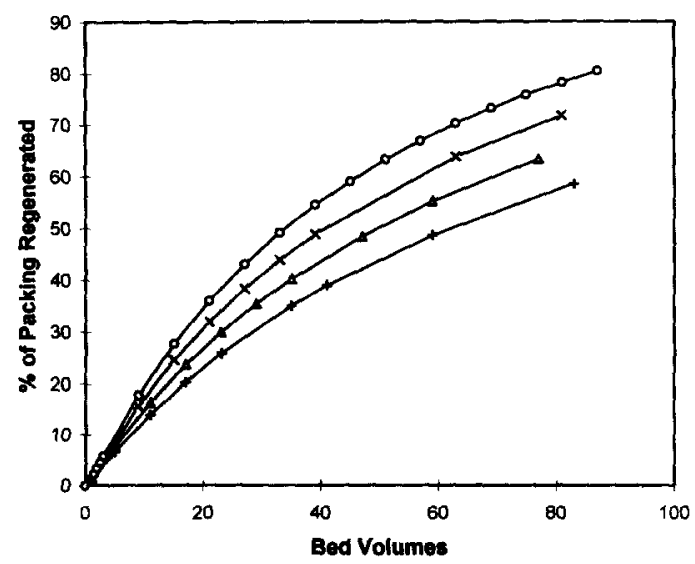

Fig. 13. Calculated $\mathrm{Ca} / \mathrm{H}$ regeneration curves for a column bed of Sargassum biomass: column length $20 \mathrm{~cm}$; flowrate $7.5 \mathrm{ml} / \mathrm{min}$. C(Ca) (O) $2500,(\times) 2000,(\triangle) 1000$ and $(+)$ $500 \mathrm{mg} / \mathrm{liter}$. exchange. The importance of ion exchange in the process of biosorption of heavy metals by algae and by peat moss was stressed by Crist et al. (1993) and by Spinti et al. (1995), respectively. Since the present work focuses mainly on the use of biomass in a packed-bed column, the remainder of the results are discussed in relation to the operation of a fixed bed, thus providing an overview of studied effects on the performance of a biosorption column.

Analysis of the performance of fixed-bed column in cyclic operation (sorption-desorption/regeneration)

Effect of equilibrium on sorption. The shape of $\mathrm{Cu}$ isotherms in Figs 3 and 4 reveal that $\mathrm{Cu}$ sorption is more favorable on Ca-biomass than on $\mathrm{H}$-biomass for all solution normalities of interest. As mentioned earlier, a "favorable" isotherm leads to a self-sharpening dynamic exchange zone in a fixed-bed adsorber, as opposed to a broadening zone brought about by an "unfavorable" isotherm. Consequently, the fact that for $C_{0}=6 \mathrm{meq} /$ liter the $\mathrm{Cu} / \mathrm{H}$ isotherm is "unfavorable" over almost the entire concentration range, whereas the $\mathrm{Cu} / \mathrm{Ca}$ isotherm is "favorable", explains the trend of breakthrough sharpening observed in Fig. 8. Furthermore, the fact that the character of the $\mathrm{Cu} / \mathrm{H}$ isotherms changes, in agreement with the ion-exchange equilibrium theory (Vermeulen, et al., 1973), from "unfavorable" at relatively high $C_{0}$ to "favorable" at low $C_{0}$ implies that the lower the $\mathrm{Cu}$ concentration in the feed to the column, the smaller the breakthrough sharpening effect caused by an increased presence of $\mathrm{Ca}$ in the biomass. For example, only minimal sharpening of the breakthrough curves was previously observed for a column feed containing $\mathrm{C}(\mathrm{Cu})=1 \mathrm{meq} / \mathrm{liter}$ (Kratochvil et al., 1995).

Role of equilibrium in metal recovery. Figure 11 demonstrates clearly that $\mathrm{HCl}$, as compared to $\mathrm{CaCl}_{2}$, desorbs more of the $\mathrm{Cu}$ from the column in a shorter period of time. Therefore, $\mathrm{HCl}$ is more effective eluent of $\mathrm{Cu}$ than $\mathrm{CaCl}_{2}$. The explanation for $\mathrm{HCl}$ being a better $\mathrm{Cu}$ eluent than $\mathrm{CaCl}_{2}$ lies primarily in the effect of equilibrium on the shape of the trailing edge of an elution peak. In fact, the trailing edge of an elution peak is a mirror image of an eluent breakthrough on a metal-saturated fixed bed. Therefore, the tailing of the elution peak obtained by using $\mathrm{CaCl}_{2}$, displayed in Fig. 11 , is simply a reflection of a broad $\mathrm{Ca}$ breakthrough on $\mathrm{Cu}$-biomass which is brought about by the convex, hence unfavorable, $\mathrm{Ca} / \mathrm{Cu}$ equilibrium isotherm seen in Fig. 6. Similarly, the steep trailing edge of the elution peak obtained when $\mathrm{HCl}$ was used as an eluent is the consequence of the highly "favorable" isotherm of $\mathrm{H}$ on Cu-biomass shown in Fig. 7.

Effect of equilibrium of $\mathrm{Ca} / \mathrm{H}$ regeneration. As explained earlier, the $\mathrm{pH}$ curves in Fig. 12 present a useful insight into the dynamics of the column regeneration process. It can be seen that, after an initial rise of $\mathrm{pH}$ from 1 to 2.1 over the first 12 bed 
volumes, the $\mathrm{pH}$ curves tend almost to plateau, yielding an increase of $0.4 \mathrm{pH}$ units over 50 bed volumes. The model prediction seen in Fig. 12 is fairly good, considering the errors associated with the measurements of $\mathrm{C}\left(\mathrm{H}^{+}\right)$with a $\mathrm{pH}$ electrode in the interval of $\mathrm{pH}$ 1-3.5. Assuming stoichiometric ion exchange between $\mathrm{Ca}$ and $\mathrm{H}$ ions, the effluent $\mathrm{pH}$ is directly related to the amount of $\mathrm{Ca}^{2+}$ being taken up by the biosorbent packing and, hence, the very slow increase of $\mathrm{pH}$ between $\mathrm{pH} 2.2$ and 3.0 implies that the column is nowhere near a complete saturation with $\mathrm{Ca}$. The computer program allows to calculate the extent of column regeneration as a function of time, as shown in Fig. 13. By comparing the breakthrough curves in Fig. 8, it can be seen that the column service time increased by 20 extra bed volumes by performing a complete $\mathrm{Ca} / \mathrm{H}$ regeneration at $\mathrm{pH} 3.5$ before $\mathrm{Cu}$ sorption. However, Fig. 13 demonstrates that within the first 20 bed volumes only $20-32 \%$ of the column is regenerated; hence, the conclusion can be drawn that $\mathrm{Ca} / \mathrm{H}$ regeneration is ineffective and indeed superfluous under the given conditions.

In order to explain the effect of the $\mathrm{Ca}$ concentration on the regeneration process, it should be recognized that the concentration of $\mathrm{Ca}$ in the feed $C_{\mathrm{CaL}}$ influences not only the mass transfer but also the equilibrium of the $\mathrm{Ca}$ sorption. The increase in $C_{\mathrm{CaL}}$ causes the driving force of the mass transfer to increase. However, since $C_{\mathrm{CaL}}=C_{0}$, the increase in $C_{\mathrm{CaL}}=C_{0}$ also leads to a more unfavorable $\mathrm{Ca}$ sorption isotherm, as shown in Fig. 5. Thus, any achieved increase in the speed of $\mathrm{Ca}$ sorption is counterbalanced by a decrease in affinity of $\mathrm{Ca}$ towards H-biomass. Consequently, as can be seen from the regeneration curves shown in Fig. 13, a four-fold increase of $\mathrm{Ca}$ concentration in the fresh regenerant results in a less than two-fold increase of the degree of column regeneration at all times.

Effect of pretreatment. Results in Table 1 show that biomass pretreated with $\mathrm{HCl}$ and $\mathrm{CaCl}_{2}$ exhibit approximately the same maximum $\mathrm{Cu}$ uptake of $74 \mathrm{mg} / \mathrm{g}$, whereas the biomass pretreated with sulfuric acid yields uptakes about $15 \%$ lower, i.e. $65 \mathrm{mg} / \mathrm{g}$. The comparison of weight losses and equilibrium uptakes in Table 1 leads to a conclusion that the acidic pretreatment extracts about $50 \%$ more matter and $30 \%$ more binding sites from the raw Sargassum biomass than does the $\mathrm{CaCl}_{2}$ pretreatment. Furthermore, the last row of Table 1 shows that $\mathrm{CaCl}_{2}$-pretreated biomass washed with acid loses about $30 \%$ of its weight while maintaining the $\mathrm{Cu}$ uptake almost unchanged at $71 \mathrm{mg} / \mathrm{g}$. Consequently, the sorption capacity of a column packed with $\mathrm{CaCl}_{2}$ pretreated biomass is expected to be lowered by approximately $30 \%$, following an acidic wash, the fact which was observed in Fig. 9. From practical point of view, the exclusion of an acidic wash from a column operation is rather inconvenient, since the "cleaning" of a bed from metals commonly present in waste streams but different from $\mathrm{Cu}$, namely $\mathrm{Fe}$ and $\mathrm{Al}$, may require acidic washing.

Applicability of fixed-bed model to biosorption. The relatively good agreement between the theoretical and the experimental breakthrough curves in Fig. 10, obtained for $\mathrm{Cu}$ sorption onto the 20 -cm-long packing of H-biomass, reveals that the set of equations (8)-(11) can be used as a suitable mathematical representation for the first biosorption cycle carried out in a fixed-bed column. The discrepancy between the predicted and the experimental breakthroughs of $\mathrm{Cu}$ for a $40-\mathrm{cm}-$ long fixed-bed column demonstrates the need for incorporating a biomass aging factor into the fixed-bed ion-exchange model. Unlike synthetic ion-exchange resins, the natural biosorbents usually exhibit leaching of their constituents into the liquid, and this aspect should be accounted for in a mathematical model applied to biosorption. Theoretically, all the parameters of the fixed-bed model, i.e. the concentration of the metal binding sites in the biomass, the equilibrium constants and the dimensionless groups $S h, P e$ and $D_{\mathrm{g}}$ are subject to change during a continuous multiple cycle operation of a column. However, not all of these parameters will exhibit the same ability to change over time. Trujillo et al. (1991) had to vary the values of the metal binding capacity and the sorption equilibrium constants for each of the metal components present in the system by an order of magnitude in order to fit the experimental breakthrough curves obtained in five consecutive cycles performed with peat-moss biomass in a column. On the other hand, as observed by other researchers (Yang and Volesky, 1996), the diffusion coefficients of ions migrating in diluted aqueous solutions, alginate gels and marine algal biomass are approximately constant. This observation suggests that the variation of the values of the overall mass-transfer coefficients of the sorbing species with time could be limited. However, more research is needed to propose a way by which the sorbent aging effects could be incorporated into the fixed-bed model.

\section{Biomass cycles for continuous column operation}

According to the results presented in this work, the operation of a biosorption column based on a Ca-cycle would offer the advantage of longer service time for sorption but would not allow the effective recovery of $\mathrm{Cu}$. Moreover, to start the $\mathrm{Ca}$-cycle $\mathrm{HCl}$ rather than $\mathrm{CaCl}_{2}$-pretreated biomass would be safer to use, since the $\mathrm{CaCl}_{2}$ pretreated biomass is prone to leaching, leading to the loss of the column sorption capacity. Consequently, the protonated biomass would have to be loaded with $\mathrm{Ca}$ before its use. Finally, it should be noted that $\mathrm{Ca}^{2+}$ ions released from the sorbent during the sorption of $\mathrm{Cu}$ by Ca-biomass may instigate the formation of gypsum depending on the concentration levels of $\mathrm{SO}_{4}^{2-}$ and $\mathrm{Ca}^{2+}$ in the waste-water. 
The $\mathrm{H}$-cycle offers the advantage of an efficient $\mathrm{Cu}$ recovery, but, on the other hand, the sorption column would not be as saturated with $\mathrm{Cu}$ at the point of the breakthrough as would a column operating on the $\mathrm{Ca}$-cycle. However, since the $\mathrm{Cu}$ sorption equilibrium isotherm changes from unfavorable to favorable, the difference between the degree of utilization of a column operating on the $\mathrm{Ca}$ - and $\mathrm{H}$-cycle decreases with a decreasing normality of the column feed. In practice, a biosorption column would be fed with low normality aqueous waste if biosorption were selected as a polishing treatment applied to the liquid discharge coming from a rougher treatment such as chemical precipitation.

The combined $\mathrm{H} / \mathrm{Ca}$-cycle offers longer service time for sorption while providing an excellent $\mathrm{Cu}$ recovery. However, the time-consuming process of $\mathrm{Ca} / \mathrm{H}$ regeneration rules out the use of this cycle unless the biomass in the column could withstand washing with a highly basic solution of $\mathrm{CaCl}_{2}$ whereby the $\mathrm{H}^{+}$released from the biomass would be neutralized with $\mathrm{OH}^{-}$in the solution phase. The $\mathrm{pH}$ would have to be adjusted with $\mathrm{Ca}(\mathrm{OH})_{2}$, since the addition of $\mathrm{NaOH}$ would cause the leaching of alginate which is considered to be the key $\mathrm{Cu}$-binding component in the marine algal biomass (Fourest and Volesky, 1996).

\section{REFERENCES}

Chapman V. J. (1980) Seaweeds and Their Uses, pp. 194-240. Chapman \& Hall, London, UK.

Chen D., Lewandowski Z., Roe F. and Surapaneni P. (1993) Diffusivity of $\mathrm{Cu}^{2+}$ in calcium alginate beads. Biotechnol. Bioengng 41, 775-760.

Chong K. H. and Volesky B. (1995) Description of two-metal biosorption equilibria by Langmuir-type models. Biotechnol. Bioengng 47, 451-460.

Coulson J. M. and Richardson J. F. (1991) Chemical Engineering, 4th edn, pp. 774-775. Pergamon Press, New York, USA.

Crist D. R., Crist R. H., Martin J, R. and Watson J. (1993) Ion exchange system in proton-metal reactions with algal cell walls. In Metals-Microorganisms Relationships and Applications, FEMS Symposium Abstracts (Edited by Bauda P.), p. 13. Societe Francaise de Microbiologie Paris, France.

Crist R. H., Martin J. R., Carr D., Watson J. R., Clarke H. J. and Crist D. R. (1994) Interaction of metals and protons with algae. 4 . Ion exchange vs adsorption models and a reassessment of Scatchard plots; ion-exchange rates and equilibria compared with calcium alginate. Environ Sci. Technol. 28, 1859-1866.

Fletcher C. A. J. (1984) Computational Galerkin Methods, pp. 246-276. Springer-Verlag, New York, USA.

Fourest E. and Roux J.-C. (1994) Improvement of heavy metal biosorption by mycelial dead biomass (Rhizopus arrhizus, Mucor miehei and Penicillium chrysogenum): $\mathrm{pH}$ control and cationic activation. FEMS Microbiol. Rev. 14, 325-332.

Fourest E. and Volesky B. (1996) Contribution of sulphonate groups and alginate to heavy metal biosorption by the dry biomass of Sargassum fuitans. Environ. Sci. Technol. 30, 277-282.

Hiester N. K. and Vermeulen H. (1952) Saturation performance of ion-exchange and adsorption columns. Chem. Engng Prog, 48, 505-516.

Helfferich F. (1962) Ion Exchange, pp. 299-319. McGrawHill, New York, USA

Helfferich F. G. (1967) Multicomponent ion exchange in fixed beds. Ind. Eng. Chem. Fundam. 6, 362-364, 424-426.

Jang L. K., Brand W., Resong, M., Mainieri W. and Geesey G. G. (1990) Feasibility of using alginate to absorb dissolved copper from aqueous media. Environ. Prog. 9 , 269-274.

Jang L. K., Nguyen D. and Geesey G. G. (1995a) Effect of $\mathrm{pH}$ on the absorption of $\mathrm{Cu}(\mathrm{II})$ by alginate gel. Wat. Res. 29, 315-321.

Jang L. K., Nguyen D. and Geesey G. G. (1995b) Selectivity of alginate gel for $\mathrm{Cu}$ vs $\mathrm{Co}$. Wat. Res. 29, 307-313.

Klein G., Tondeur D. and Vermeulen T. (1967) Multicomponent ion-exchange in fixed beds. Ind. Eng. Chem. Fundam. 6, 339-350.

Kratochvil D., Fourest E. and Volesky B. (1995) Biosorption of copper by Sargassum fluitans biomass in fixed-bed column. Biotechnol. Lett. 17, 777-782.

Liberti L. and Passino R. (1982) Simplified method for calculating cyclic exhaustion-regeneration operations in fixed-bed adsorbers. Ind. Eng. Chem.. Process Des. Der. 21, 197-203.

Michaels A. S. (1952) Simplified method of interpreting kinetic data in fixed-bed ion exchange. Ind. Eng. Chem. 44, 1922-1929.

Mills R. and Lobo V. M. M. (1989) Self-Diffusion in Electrolyte Solutions: A Critical Examination of Data Compiled From the Literature. Elsevier, New York, USA.

Percival E. and McDowell R. H. (1967) Chemistry and Enzymology of Marine Algal Polysaccharides, pp. 1-25, 157-165, 174-179, 190-191. Academic Press, London, UK.

Schiewer S. and Volesky B. (1995b) Modeling of the proton-metal ion exchange in biosorption. Environ. Sci. Technol. 29, 3049-3058.

Schiewer S. and Volesky B. (1995a) Mathematical evaluation of the experimental and modeling errors in biosorption. Biotechnol. Techniques 9, 843-848.

Schiewer S. and Volesky B. (1996) Modeling of multi-metal ion exchange in biosorption. Environ. Sci. Technol. 30, 2921-2927.

Selke W. A. (1956) Mass transfer and equilibria. In Ion Exchange Technology (Edited by Schubert J. \& Nachod. F. C.), pp. 53-62. Academic Press, New York, USA

Shallcross M., Herrmann C. C. and McCoy B. J. (1988) An improved model for the prediction of multicomponent ion exchange equilibria. Chem. Engng Sci. 43, 279-288.

Spinti M., Zhuang $\boldsymbol{H}$. and Trujillo E. M. (1995) Evaluation of immobilized biomass beads for removing heavy metals from wastewaters. Wat. Environ. Res. 67, 943-952.

Tan H. K. S. and Spinner I. H. (1994) Multicomponent ion exchange column dynamics. Can. J. Chem. Engng 72 , 330-341.

Thom D., Grant G. T., Morris E. R. and Rees D. A. (1982) Characterisation of cation binding and gelation of polyuronates by circular dichroism. Carbohydr. Res. 100, $29-42$

Trujillo E. M., Jeffers T. H., Ferguson D. and Stevenson H. Q. (1991) Mathematically modeling the removal of heavy metals from wastewater using immobilized biomass. Environ. Sci. Technol. 25, 1559-1565.

Vermeulen T., Klein G. and Heister N. K. (1973) Adsorption and ion exchange. In Chemical Engineers Handbook, 5th edn (Edited by Perry R. H. and Chilton C. H.), Chap. 16. McGraw Hill, New York, USA

Volesky B. and Prasetyo I. (1994) Cadmium removal in a biosorption column. Biotechnol. Bioengng 43, 1010-1015.

Yang J. and Volesky B. (1996) Intraparticle diffusivity of $\mathrm{Cd}$ ions in a new biosorbent material. $J$. Chem. Technol. Biotechnol. 66, pp. 355-364 